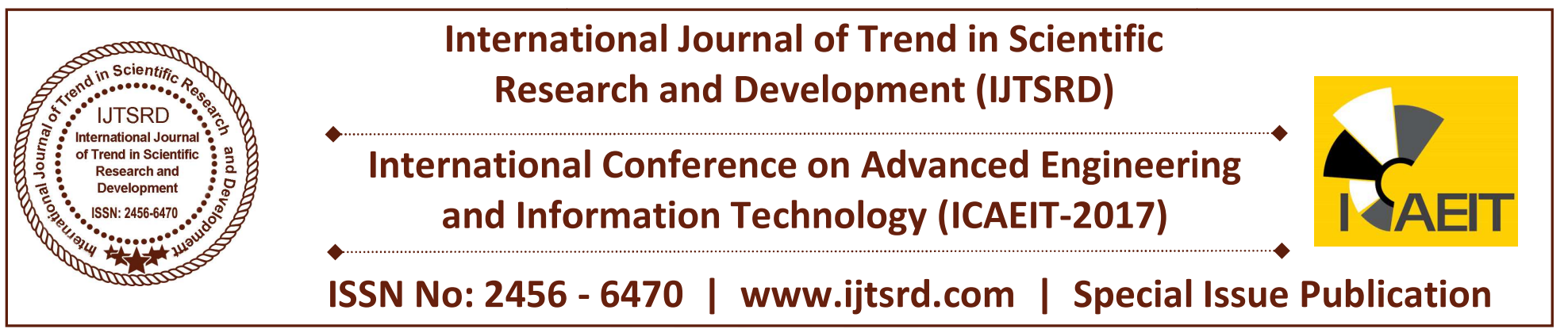

\title{
Web-based Solution to Sports Management Reform: Case of a Linton University College
}

\author{
Nyabinde David Tatenda ${ }^{1}$, Noor Zuhaili Binti Md Yasin ${ }^{2}$, Sheik Mohideen Abdul Latheef ${ }^{2}$ \\ ${ }^{1}$ Linton University College in collaboration with Leeds Beckett University, Negeri Sembilan, Malaysia \\ ${ }^{2}$ SEEMIT, Linton University College, Negeri Sembilan, Malaysia
}

\begin{abstract}
This paper presents a Web based Sport Management System which allowed sports administrator to manage the sports event at an educational institution. The projects' aim was to help improve the management of sports as well as allowing the students to be aware of the sporting events at the university. The development of the system primarily focused on implementing the most important functionalities required by the users as well as meeting the objective set. Accordingly, a web based system is developed as a solution and it will centralize information regarding sports for an institution. Using evolutionary prototyping was important as the system was to be used by a huge number of users, so important feedback was much needed. Although upon implementation, various changes were made to appeal the required functionalities and also from users feedback. However, not all feedback from users were implemented due to the developers' opinion regarding the feedback.
\end{abstract}

Keywords: Sports management, web-based sports management system, implementation, functionalities, objective set, centralize information, evolutionary prototyping, user feedback

\section{INTRODUCTION}

Every institution aspires to maintain proper records of students and information regarding events that are happening around the campus for operational purposes. Developing a sports management system will scrap off the traditional method whereby a sports director has to compile the details of sports manually and on the other hand whereby a student has to look for a team captain or a person in charge so as to register to a club or society.

Planning, organising and managing time are factors which will have an impact of on management which will in turn lead to lack of commitment by students to participate in sporting activities at a university that are organised. In order to attain full commitment, henceforth require a platform whereby they can access information at their fingertips. In order to eradicate the issue a system has to be developed. Furthermore, there is need for a university to have a proper method to store records of their co-curricular activities as well as knowing who is in charge of a which particular sport.

The project is developed as web based application which will work for a specified institution for managing the sports. However, modifications can be done in time so as to allow the application to function with other co- curricular activities. The target users of the system are students, coaches and an admin who in overall oversees all the important details pertaining sports at a university.

\section{OBJECTIVES}

The objective set for developing the system is shown as follows:

$>$ Develop a web-based application for managing sports

$>$ Implement a database to store admin staff and student data

Develop a system which allows a sports manager to update detail of all sporting events 
$>$ Develop a system which allows students to register themselves to a particular sport

$>$ To examine and understand current sports management system

$>$ To test and evaluate the newly developed system

$>$ To make it easier for students to join clubs and societies

$>$ To generate reports that will help the sports administrator to know how each sport is performing

$>$ To develop a system whereby a person in charge of a sport can manage their sports club

To develop a system which allows selection of participants for an event

\section{CONCEPTS OF SYSTEM SOLUTION}

The current system provided at the institution proves to be inefficient as it takes too much time to inform students about sports in the campus. Furthermore, students typically find it hard to know the training days and upcoming events of their clubs and societies. The main importance of the proposed system is to have a platform where information can be shared securely within the institution as well as having a platform where clubs and societies can have members register through it as it will save both clubs and students the hassle involved when registering a new member or registering as a member respectively. Some functionalities that will improve the management of sports at the institution are listed below:

\subsection{ADMIN SIDE}

The main focus is to have a place whereby a sports director will be able to update information that relates to various clubs and societies so that it eliminates some paperwork. Meaning that, if a student is to register online to a club or society, there is no need of entering the details manually again and this saves valuable time. Furthermore, records saved can be used for future references as information will be centralized.

\subsection{STUDENT SIDE}

As a new student, there is a great possibility that student will be interested in joining a club or society but they do not know anyone at that point. So, the system provides a platform where it is easier to select which club student would be interested to join. Furthermore, it provides the training schedule of the club which makes it easier if a student is interested to join the training. This eliminates the struggle to look for team captains, set appointments to register and lack of knowledge on how the club is setup. However, this functionality requires much more control as the students would keep on spamming the coach. Implementing this functionality would mean that once the student deregisters from a club, they would be restricted to join the club for a certain period of time. On the other hand, the student interface would be improved by having a page which allows the users to view their own profile which will comprise of a summary of the clubs they are involved in, the request which are still pending and the details of their role to the club.

\subsection{CLUB AND SOCIETY SIDE}

The system eliminates the time a club or society opens a booth to register new members, for all students have limited time during working hours as they are required to attend lectures. The system makes it easier for a club to keep track on their upcoming events as well as the participants of the events. It also makes it easy to disseminate information regarding their training schedule. However, opening of booths to register students will not be removed entirely as some updates and confirmation might be required to do manually. Workload will also be reduced for clubs and societies as they will be required to approve new members.

\section{SOFTWARE USED FOR SYSTEM SOLUTION}

Microsoft Visual Studio (VS) is a software whereby computer programmers have the platform to develop software and applications. There are various versions of VS and these include the professional version, enterprise version and the community version. For this project, VS community was selected as it is an open source whereby anyone can download and start developing applications without paying for it. However, some function which are available for the professional and enterprise are not available for the community version.

\section{LANGUAGE USED FOR SYSTEM SOLUTION \\ 5.1 C-SHARP}

$\mathrm{C \#}$ is one of the most commonly used programming languages in this day and age. The concept is similarly the same as that of $\mathrm{C}++$ and it is very similar to Java. The most basic structure of a $\mathrm{C \#}$ code includes classes and objects. Each class has members that define the data and behavior of the class. 
Furthermore, objects are instances of a class. The classes can be defined to be accessed publicly or privately by other classes defined in a program. C\# is an Object Oriented language. For this project, C\# will be used as the back-end programming language as it works efficiently with ASP.NET.

\subsection{JAVA}

Java language programming model is based on the concept of Object Oriented Programming, which the language's features support. Fundamentally, the Java programming language begins with packages, which is the language's namespace mechanism. Within the packages, classes are found and furthermore within classes there are methods, variables, constants and more. Java programming language is platform independent meaning that it is not compiled into platform specific machine but rather into platform independent byte code. The byte code will be distributed over the network and interpreted by the Java Virtual Machine (JVM) on any platform that it is being run on.

\section{METHODOLOGY}

For the system solution, evolutionary prototyping which falls under prototyping was chosen as the methodology to manage the development of the sports management system.

Evolutionary prototyping proved to be a suitable methodology as it created room for improvement on the system, thus, identifying additional requirements and then add them to the prototype which means that there is room for continual refinement and rebuilding. Furthermore, evolutionary prototyping created room for removing features that are not required even though they were included in an earlier prototype.

Table 1: Input data

\begin{tabular}{|c|c|c|}
\hline Tree species & Floating test & $\begin{array}{c}\text { HACH test } \\
\text { meter }\end{array}$ \\
\hline Albizia lebbeck & $100 \%$ & $100 \%$ \\
\hline Tamarindus indica & $100 \%$ & $100 \%$ \\
\hline
\end{tabular}

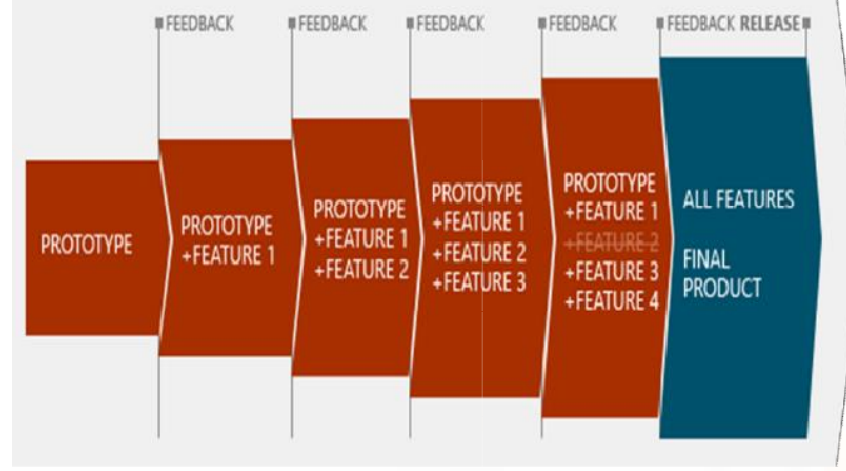

Figure1. Evolutionary Prototyping Source (Mourzenko, 2014)

\section{IMPLEMENTATION}

The interface of the start-up page was developed in a way that it is less confusing to the user on where to go next. After creating a first prototype, the first page of the system was directly the login page. However, after feedback from random users, it was noted that a home page was required and it was implemented and it can be seen from the diagram below.

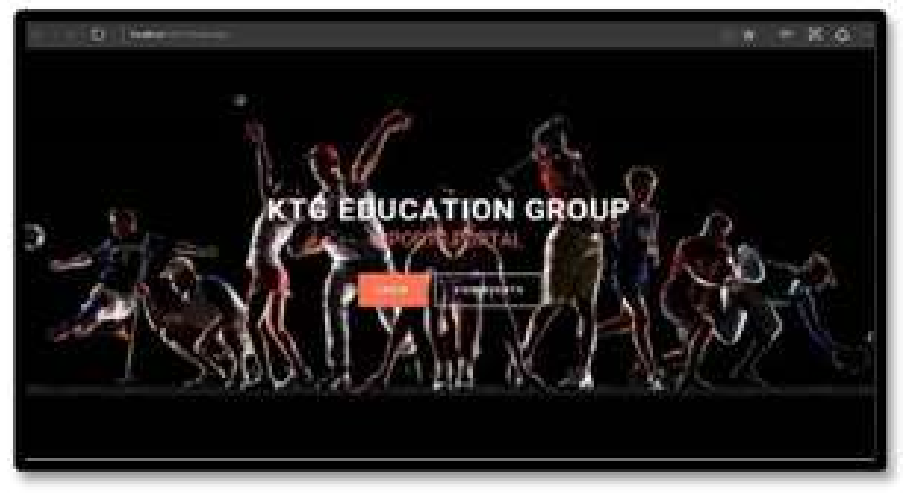

Figure 2: Home Page

An additional change was made to the interface as well by introducing a new page that allows users who are not signed in to view upcoming and past events of the university. This was done in the form of providing a calendar on a page and the date bound to it is selected from the database. Below is an image which shows how the page is set up.

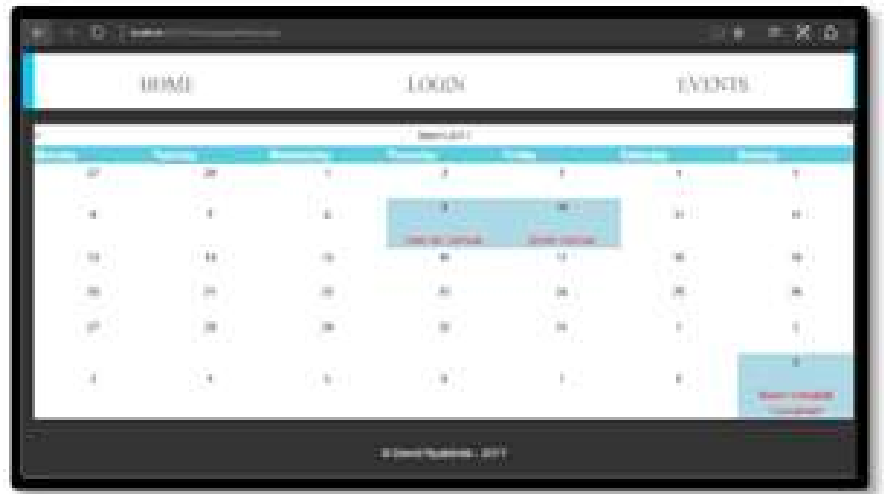

Figure 3: Events Page. 
The diagram below shows the login page of the system. The purpose of this page is to limit access of information to current registered students, coaches and admin only. A user can select the user type from the left hand side and enter their valid credentials to proceed to the next page.

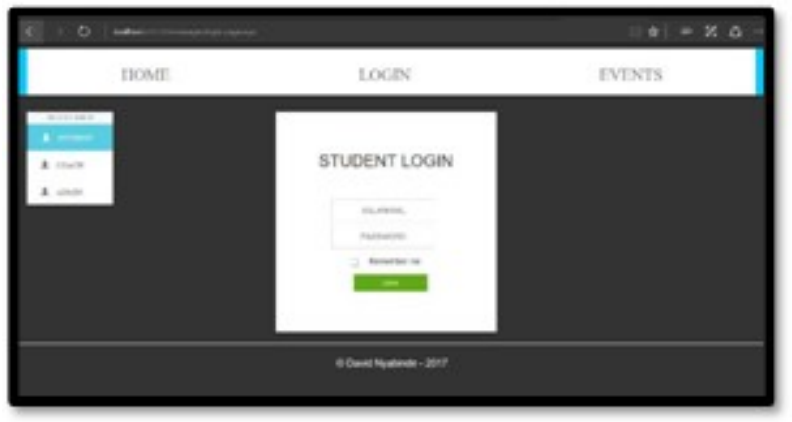

Figure 4: Login Page

\subsection{ADMIN SIDE}

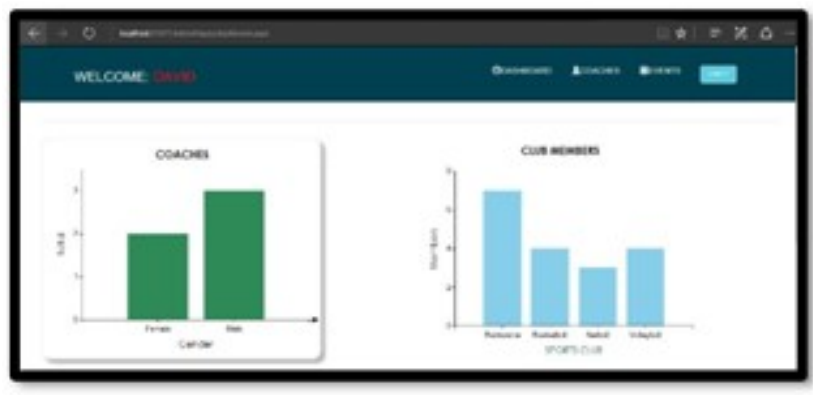

Figure 5: Admin Home Page

The figure above details the home page of the admin. This purpose of this page is to display various charts report that the admin can use to assess the sports system.

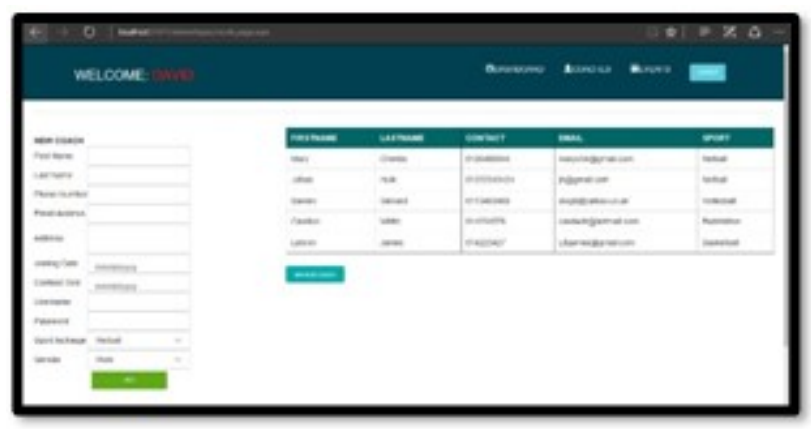

Figure 6: Admin Coach Pages

The figure above displays a page which the admin can use to register a new coach and assign a sport to that particular coach. Furthermore, it allows the coach to update and delete a coach. Valid input is required for this process to be completed. The implementation of dynamic page when the admin creates a new sport would be the greatest improvement as it will save the time it will take to create new page by coding. After a few prototypes, this feature was suggested but however the developer could not risk recreating the pages due to limited time constraint to complete the project as well as difficulties in implementing this type of feature. An additional improvement to the admin side would be allowing the user to delete multiple records at the same time, for example, deleting events. The current system only allows the user to delete the records one by one

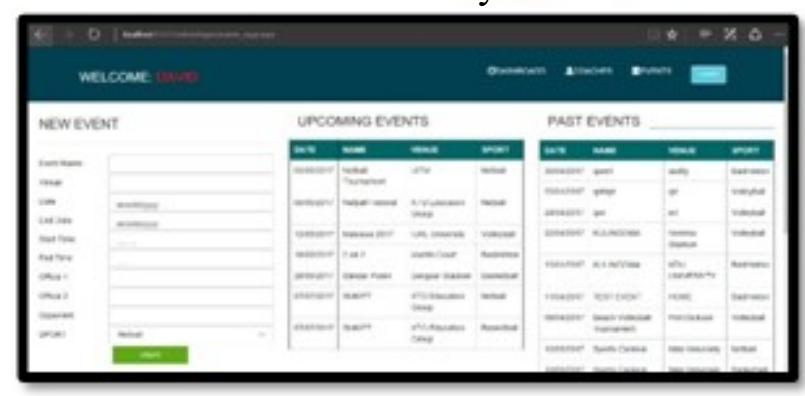

Figure 7: Admin Event Page

The figure above shows a page in which the admin can use to create an event, update an event and delete and event. In order for the admin to create a new event, all fields must contain valid information

\subsection{STUDENT SIDE}

After a student insert a valid user name and password, they are redirected to the home page for all active sports clubs.

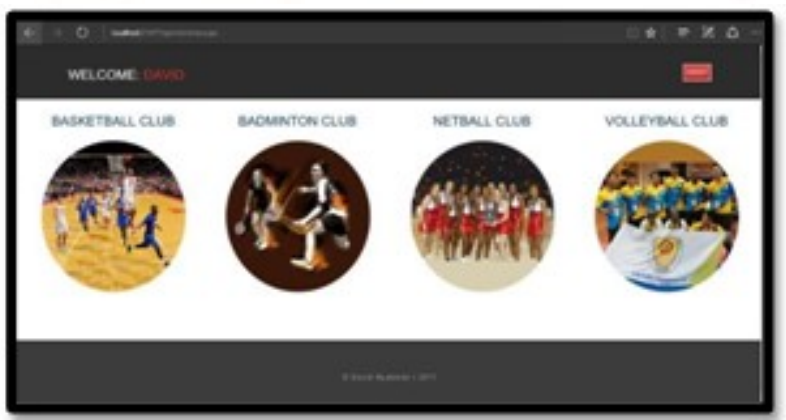

Figure 8: Sports Home Page

The function of the page above is to allow a student to select a desired club so that they can view the details of the club. An improvement to the student interface would be incorporating the ability of the student to change the colour of the interface at will as different users prefer the different colours. Furthermore, a photo gallery for each sport would be ideal as it will help the clubs to attract more members. An additional improvement would be granting the student thee ability to leave a club at any time. However, this functionality requires much more control as the students would keep on spamming the coach. Implementing this functionality would mean that once the student deregisters from a club, they would be 
restricted to join the club for a certain period of time. On the other hand, the student interface would be improved by having a page which allows the users to view their own profile which will comprise of a summary of the clubs they are involved in, the request which are still pending and the details of their role to the club.

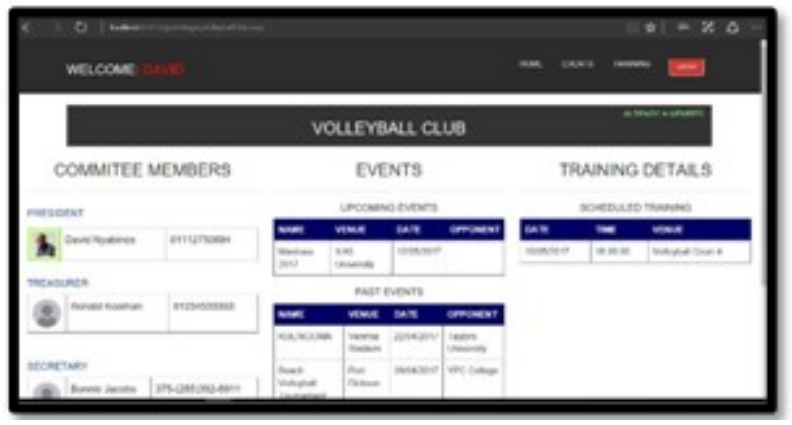

Figure 9: Sports Club Page

From the figure above, after a student selects their desired sport, they will be redirected to this page and from there, they are able to view the committee members of the club, upcoming event as well as the past event. The student can also view the training schedule of the club as well as request to join a club if they are not a member of the club.

\subsection{COUCH SIDE (CLUB AND SOCIETY)}

After a successful login, the coach will be able to manage the club that they are assigned to.

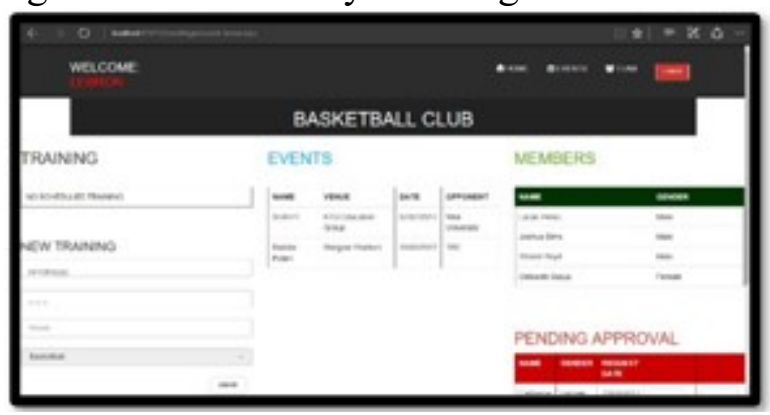

Figure 10: Coach Home Page

The coach home page displays the content based on the sport the coach is in charge of. This page allows the coach to schedule training, approve or decline membership requests and view upcoming events for their particular sport. Furthermore, a tactics page was suggested whereby coach can upload files about the sport, thus, the rules of the sport. This would help new members who are not familiar with the sport to read the basic rules, which will make it easier when they attend a training session.

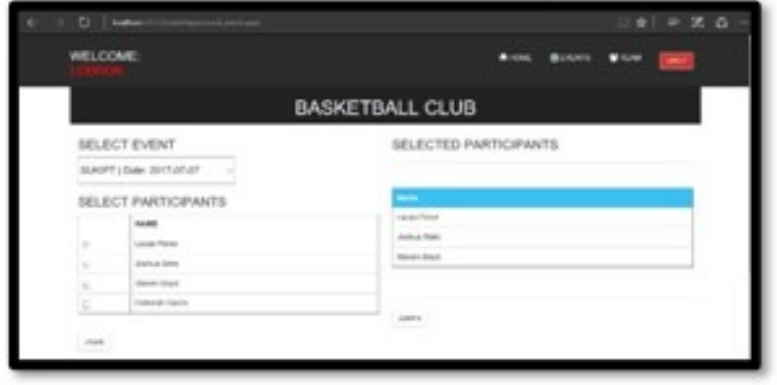

Figure 11: Coach Events Page

The coach events page allows the coach to make a team selection for an upcoming event as well as managing the participants list.

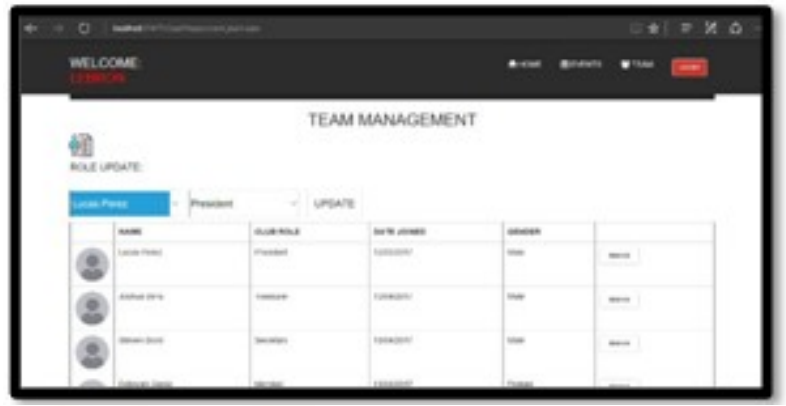

Figure 12: Coach Team Management Page

The page above allows the coach to manage the current members of the club for example, changing the role of the student. The page also allows the coach to remove members from the club.

\section{FUTURE ENHANCEMENT}

After the evaluation of the system, most requirements were met but this does not rule out the possibility of improvements to the system. Although some functionalities were beyond the scope of the project, for instance, the ability to manage match details of each sport, it will be perfect to incorporate it in the near future. The overall system design will also be improved by adding more flash graphics as well as confirmation messages after completing certain tasks, for instance, if a student clicks the join club button, there should be a message to ask the student if they really want to join the club. Adding this feature would be a great improvement.

\section{CONCLUSION}

Although completing the system was inevitable due to limited time to complete the project, the system produced met the objectives set during the planning phase. This was achieved by using Evolutionary Prototyping which enable refinement of the system. The overall design and functionalities were acceptable to users. Nonetheless, more design technics could 
have been incorporated but due to the size of the project, it was fairly wide-ranging.

However, during the entire period of this project, the developer gained more skills, for instance, using charts on a web interface using ASP.net. Furthermore, report writing, problem solving and creativity are amongst the skill the developer improved on and these skills are important as the current industry might require them, hence, increasing employability chances. During the course of this project, open source tools were used, such as bootstrap, and this removed the possibility of the developer incurring additional costs. This project is the first step towards improving the way sports are managed at a university such Linton University College. During the course of the project, it was noted that users would favour using the system as it will make their sporting experience better at a university.

\section{ACKNOWLEDGEMENT}

Advice given by Dr. Mia Torres, Madam Manimala Veeraiyah and all Faculty of Engineering and Technology group members with a great help in this project. It is a pleasure to have them for their patient guidance, encouragement and useful critiques throughout the research process. My grateful thanks also extended for the people that helping whether direct or indirectly in my documentation writing. Finally, I would also like to extend my thanks to my friends and family for their support and encouragement during my studies.

\section{REFERENCES}

1. Anon (2016) Clubs List [Internet]. Available from:

$<$ https://www.cardiffstudents.com/activities/au/list $>$ [Accessed 10 December 2016].

2. Cardiffstudents.com. (2017). Athletic Union. [online] :https://www.cardiffstudents.com/activities/au/ [Accessed 6 Jan. 2017].

3. Chan, M. (2017). Using Color in Web Design. [online] Webspec Design. Available at: https://www.webspecdesign.com/2017/03/the importance-of-color-in-web-design/ [Accessed 20 Mar.2017].

4. Mourzenko, A. (2014). Evolutionary prototyping : features are aggregated to the prototype to build the final product.. [image] Available at: https://softwareengineering.stackexchange.com/qu estion s/253574/why-we-need-throw-awayprototyping [Accessed 11 Mar. 2017].

5. Righthandtech.com. (2017). Software Testing - Its Purpose and Definition. [online] Available at: http://www.righthandtech.com/softwaretesting.php [Accessed 4 Mar. 2017].

6. Rouse, M. (2015). What is prototype? - Definition from WhatIs.com. [online] SearchManufacturingERP. Available at: http://searchmanufacturingerp.techtarget.com/defi nition/ prototype [Accessed 5 Feb. 2017]. 